\title{
CERVANTES ENTREMEZISTA - A ARTE DE BATIZAR SUAS PERSONAGENS
}

\section{Célia Berrettini}

Autor de Numância - a peça tão elogiada por Schlegel, Schopenhauer e Goethe, e de há muito tida como a melhor tragédia espanhola do século XVI e das mais importantes de todo o Teatro Espanhol -, compôs ainda Cervantes, como se sabe, várias outras peças, entre as quais sobressaem os Entremeses. (1) Apesar de curtas e despretensiosas, são talvez suas obras-primas: nelas, o espírito reflexivo do autor e sua experiência da vida humanizam as máscaras de suas personagens "marionnettes", transformando-as em complexas criaturas dramáticas; nelas, o seu humor irrompe, provocando a hilaridade, diante de determinados seres e em determinadas situações da realidade social, e criando, como diz Robert Marrast, um "Teatro em liberdade" Nenhum fito de "edificação política, religiosa ou moral anima o autor e ele cria situações dramáticas, cuja exposição, desenvolvimento e desenlace permanecem à margem das normas 'oficiais' que deveriam reger a conduta pública e privada dos indivíduos" (2)

Já Pfandl reconhecia a originalidade e superioridade de Cervantes, diante dos outros entremezistas, salientando em suas criações: a perspectiva e o ambiente que faltaram nos "pasos" de Lope de Rueda, seu antecessor, e que fazem com que tudo se mova "em uma esfera sempre exatamente descrita", seja numa casa, seja numa rua; os caracteres das personagens, bem definidos mediante poucos traços que já thes delineiam a individualidade, seja o velho ciumento, seja o pouco inteligente candidato a alcaide, entre outros; o humor, que cria uma atmosfera de "alegria risonha e clara"; a construção perfeita, merecendo especial realce El Retablo de las Maravillas, autêntica obraprima do gênero; e decência e bom gosto, em relação aos entremezes anteriores e posteriores. (3) E inegável é, hoje, a necessidade de

(1) - Cervantes - Entremeses. Madrid, Espasa - Calpe, 1952.

(2) - Francisco Ruiz Ramón. Historia del Teatro Español. Madrid, Alianza Ed., 1967, p. 137.

(3) - Ludwig Pfandl. Historia de la Literatura Nacional Española en la Edad de Ore. Bilbao, Gustavo Gili, 1952, pp. 489-93. 
reconhecer em Cervantes o grande entremezista e o verdadeiro criador do gênero, pois alçou à categoria literária os esboços de Lope de Rueda, superando com seus oito entremezes as possibilidades dramáticas contidas naquelas antigas peças.

Cervantes, satírico observador da realidade, representa a criatura humana e a sociedade de seu tempo, em seus alegres e jocosos entremezes. Ora, é a visão satírica dos velhos que se casam com jovens, o que os leva à tortura do ciúme sem solução - El Viejo Celoso; ora, é a graciosa captação da infelicidade conjugal, através do desfilar de casais diante do juiz a quem expõem seus conflitos, solicitando o liberador divórcio - El Juez de los Divorcios; ora, é a cômica apresentação dos candidatos às eleições aldeãs - La Elección de los Alcaldes de Daganzo; ora, o cômico confronto do soldado e do sacristão, representantes de suas profissões, e pretendendo ambos à mão de uma jovem - La Guarda Cuidadosa; ora, ainda, a divertida e hábil sátira dos dois sentimentos típicos da época dos Austrias horror da bastardia e do sangue com "contaminação judaica" - naquele que pode ser considerado o melhor entremez cervantino: El Retablo de las Maravillas. Esses e os outros três entremezes, que aparecem reunidos sob o título Ocho Comedias y Ocho Entremeses, em 1615, fazem desfilar diante do leitor ou espectador, um traço profundo da condição humana ou da natureza social, numa visão que seria amarga, não fosse o tom vivo e desenvolto, que leva o homem a rir do homem.

Vivacidade, desenvoltura, malícia, habilidade no manejo do diálogo caracterizam os entremezes. Mas a graça provém inclusive dos nomes de muitas das personagens que vivem através dessas curtas peças: se algumas foram batizadas com nomes de uso corrente, que nada apresentam de especial, já outras receberam curiosas designações, merecendo que nelas nos detenhamos, tais como nas que surgem em dois entremezes: La Elección de los Alcaldes de Daganzo e El Retablo de las Maravillas.

Quanto às personagens do primeiro entremez, tanto as que vão eleger o alcaide de Daganzo - pequena aldeia de lavradores, perto de Madrid -, como as que se apresentam como candidatos, todas são comicamente batizadas pelo autor. Ao primeiro grupo pertencem: o Regedor Panduro, o Regedor Algarroba, o Bacharel Pesuña, o Escrivão Estornudo, nomes graciosamente sugestivos das características que apresentam. O de Panduro, o regedor que abre o entremez, com palavras de paz e confiança, é sumamente significativo, sobretudo se recordarmos o refrão - e Cervantes deles fez muito uso - , que o nome sugere e que a atuação da personagem comicamente ilustrará. Trata-se do refrão "A pan duro, diente agudo", que, pelo que nos explica o Diccionario publicado pela Real Academia Española, "aconseja la actividad y la diligencia que se debe poner para superar la di- 
ficultad en las cosas arduas y dificultosas." $E$ é isso que pretende Panduro, ao tratar da questão da escolha de alcaide. Quanto aos outros diligentes eleitores, seus nomes não são menos graciosos, pelas possíveis conotações: Algarroba (alfarroba, planta de vagens com sementes adocicadas que são dadas como alimento às pombas, aos bois e principalmente aos cavalos); Pesuña (casco); e Estornudo (espirro)

E, reunidos os quatro, vão examinar os quatro candidatos, cujos nomes dão margem a risonhas interpretações: Francisco de Humillos, Miguel Jarrete, Juan Berrocal e Pedro Rana. Humillos, que significa "vanidad, presunción y altanería", bem caracteriza o primeiro pretendente à alcaidia, , pois ele chega a vangloriar-se de sua ignorância, e esta, como sabemos, era uma possível prova de "sangre limpia" Explica-nos Américo Castro que o Imperador Carlos V escolhia para seus conselheiros os que, por sua linhagem de lavradores - e portanto incultos e analfabetos -, não fossem suspeitos de judaísmo. (4)

A' pergunta, cômica, do Bacharel, se sabe ler, responde Humillos:

No, por cierto,

Ni tal se probará que en mi linaje

Haya persona de tan poco asiento,

Que se ponga a aprender esas quimeras

Que llevan a los hombres al brasero,

$Y$ a las mujeres, a la casa llana.

Sé de memoria

Todas cuatro oraciones, $y$ las rezo

Cada semana cuatro y cinco veces.

Con esto, y con ser yo cristiano viejo,

Me atrevo a ser un senador romano.

E necessário se torna chamar a atenção para a aliança dos nomes: Francisco de Humillos. Se Francisco, pela influência religiosa, pode ser conotado com a humildade, a simplicidade, já Humillos é sua negação; e a personagem, comicamente, se jacta de sua ignorância, ignorância que implica sua "limpieza de sangre"

Miguel Jarrete é o segundo examinado pelo "douto" conselho, e seu nome bem de acordo está com algumas de suas especialidades; além de apenas saber soletrar, confessa que:

(4) - Américo Castro. De la Edad Conflictiva. Madrid, Taurus, 1963, p. 197. 
Sé calzar un arado bravamente,

$\mathbf{Y}$ herrar, casi en tres horas, cuatro pares

De novillos briosos y cerreros;

$\mathbf{Y}$ soy cristiano viejo como todos.

Jarrete, explica o Diccionario já citado (coincidindo o espanhol e o português), significa "la parte alta y carnuda de la pantorrilla hacia la pierna" e também "corvejón". Ora, este último termo, em Veterinária, indica a articulação "a la cual se deben los principales movimientos de flexión y extensión de las extremidades posteriores en los cuadrúpedos" E Jarrete lida destramente com os animais, o que, segundo ele, o habilita para alcaidia à qual pretende, apoiado ainda pelo fato de ser "cristiano viejo"

Juan Berrocal, o terceiro candidato, com sua profissão de "catavinos" (provador de vinhos), comicamente se apresenta como muito bem credenciado para exercer o cargo, ao dizer, com orgulho:

Sesenta y seis sabores estampados

Tengo en el paladar, todos vináticos.

Sendo "Berrocal" o lugar repleto de "berruecos" isto é, o "tolmo granítico", ou seja, "peñasco elevado que tiene semejanza con un gran hito o mojón", nada há de mais oposto entre o que seu nome sugere e a figura oscilante que ele deve frequientemente oferecer, após ter provado os "sesenta y seis sabores" de vinho. . Aliás, o Diccionario já citado nos informa que, figurada e familiarmente, "berrueco" significa "borracho que anda de taberna em taberna" Cervantes batiza, pois, a sua grotesca personagem, mediante a oposição entre o que o nome sugere e a silhueta do portador de tal nome. Se avançarmos, porém, no estudo dos vocábulos, perceberemos com que habilidade Cervantes lida com os significantes e os significados; e é suficiente notarmos que Berrocal exerce a profissão de "catavinos", cujo sinônimo é "mojón" (ambos termos usados no entremez) Ora, "mojón" também significa "señal permanente que se pone para fijar los linderos de heredades, términos y fronteras", e, por extensão, "señal que se coloca en despoblado para que sirva de guía" Bom guia seria, pois, Berrocal para a aldeia de Daganzo. Cômico jogo de palavras do malicioso Cervantes? Excessiva fantasia da interpretação? A verdade é que Cervantes criou, como sabemos, todo um entremez - El Retablo de las Maravillas -, em que a palavra engendra a ação, fazendo que uma personagem chegue a dançar com "la Nada hecha palabra", segundo a feliz expressão de Joaquín Casalduero. (5)

(5) - Joaquín Casalduero. Sentido y Forma del Teatro de Cervantes. Madrid, Ed. Gredos, 1957, p. 217. 
Quanto à designação do último candidato, não é menos divertida, pela riqueza de sugestões. Trata-se de Pedro Rana. Se a expressão "no ser rana" significa "ser hábil y apto en una materia o sobresaliente en otro concepto cualquiera", concluímos que "ser rana" tem o sentido de "não ser vivo, esperto", e Pedro Rana é justamente o contrário. Entre os quatro pretendentes ao cargo de alcaide, é ele o mais sagaz: é a personificação da sagacidade. Ao tomar a palavra, para apresentar-se, diz:

\section{Como Rana,}

Habré de cantar mal; pero, con todo,

Diré de mi condición, y no de mi ingenio.

E a seguir, dá toda uma lição de demagogia, a ponto de Algarroba reconhecer a beleza de seu "canto":

! Vive Dios, que ha cantado nuestra Rana

Mucho mejor que un cisne cuando muere!

E' ele a encarnação da habilidade política e, no final, se bem que a eleição tenha ficado adiada para o dia seguinte, parece já decidida a sua vitória: até mesmo Jarrete, seu próprio rival na batalha eleitoral, reconhece-lhe o fascínio, dizendo:

(Rana) no solamente canta, sino encanta.

Tanto Rana, o vencedor desta peça, como Tontonelo, o sábio criador do "Retablo de las Maravillas" do segundo entremez, que passaremos agora a focalizar, são dois dos nomes que designam qualidades opostas às dos seus portadores, constituindo-se numa prova a mais - se é que não a temos, sob outros aspectos - da malícia e ironia cervantina, que lança mão de tal procedimento como recurso auxiliar para a cômica caracterização de suas personagens.

Em El Retablo de las Maravillas, que é uma sátira bastante aguda das hiprocrisias e convenções sociais, apreciamos o apogeu da arte cervantina, no que diz respeito ao poder da palavra: graças à palavra de dois hábeis vigaristas, o teatrinho, ou melhor, um palco vazio vai sendo visitado por imaginárias aparições, enquanto os espectadores reagem menos ou mais acaloradamente, com gritinhos ou brados, até alvoroços e estardalhaços, como se lá estivessem vendo tudo o que lhes "é exibido", verbalmente. E a burla criada pela palavra, explorando a pusilanimidade e a hipocrisia social generalizada - ou, se quisermos, a imbecilidade humana - , pois ninguém se atreve a negar a existência real do que lhe "é mostrado" Se alguém o fizer, será o público reconhecimento da bastardia ou da contaminação judaica, preocupações comicamente satirizadas pelo autor, se bem que este entre- 
mez se preste a um leque de interpretações. Ao oferecerem o espetáculo às autoridades da aldeia, Chirinos e Chanfalla - os proprietários do "Retablo" criado pelo sábio Tontonelo - haviam assinalado as condições para que todos os espectadores pudessem admirá-lo: o filho bastardo ou o judeu converso, marcados ambos por tão grande deficiência, estariam impossibilitados de "ver", e conseqüentemente, de "apreciar" a exibição.

Sem nos determos nos problemas das fontes do entremez, nem na sua perfeita estrutura dramática, bem como tampouco na vivacidade dos diálogos, vejamos os nomes das suas personagens: nomes pitorescos, sugestivos, cômicos. De início, temos os enganadores Chanfalla e Chirmos, ajudados por Rabelín, o músico que deve preencher, com sua arte, o vazio que antecede a entrada das invisíveis figuras. Ora, o nome Chanfalla parece ter sido escolhido, tendo em vista um outro termo: "Chanfaina", que em "Germanía" (maneira de falar dos ciganos, ladrões e rufiões, e que era apenas usada por eles) significa "rufianesca" ou "costumbre de los rufianes" Sendo Chanfalla um pícaro, um embusteiro, seu nome, com ligeiras alterações — quase imperceptíveis, oralmente - é muito sugestivo quanto ao seu carater picaresco. E o nome da sua companheira, Chirinos, parece ter sido usado por Cervantes, por analogia com "Chirinola", já que "Chirinola" é "un juego de muchachos" e, na linguagem figurada e familiar, "estar de chirinola" significa "estar de fiesta o de buen humor"; e Chirinos, para empreender o "jogo teatral das maravilhas", deve estar de bom humor, com ar festivo, na perspectiva do que farão - ela e o parceiro - , explorando a credulidade, ou melhor, as debilidades dos espectadores. Nesse jogo, o par de pícaros conta com a ajuda de Rabelín, nome que é o diminutivo de "rabel", o instrumento que a personagem toca não muito bem, a julgar pelos ásperos comentários do Alcaide Benito Repollo, e que é indicador de sua diminuta estatura, tão ridícula quanto a sua música. E o que exprime Chirinos, no início da burla:

Maravilla será si no nos apedrean por sólo el Rabelín; porque tan desventurada criaturilla, no la he visto en todos los días de mi vida.

Quanto ao público, está composto das personalidades da aldeia, a saber: o Alcaide Benito Repollo, a filha Teresa Repolla e o sobrinho; o Regedor Castrado e a filha Juana Castrada; o Escrivão Pedro Capacho, além do Governador, cujo nome só aparece rapidamente no entremez. São nomes que, pitorescamente, revelam as características das personagens focalizadas pelo malicioso entremezista. Assim, o Alcaide Benito Repollo é o rude e ignorante lavrador, e o nome com que Cervantes o batizou bem indica suas atividades como agri- 
cultor Rústico, usando incorretamente palavras e frases, vem sempre corrigido pelo letrado Pedro Capacho: se Repollo, maravilhado com as palavras da pícara Chirinos, as qualifica de "sentencia ciceronianca", passa o outro à pronta correção, ironicamente respeitosa: "Ciceroniana quiso decir el Señor Alcalde Benito Repollo"; se, ao tratarem das condições de pagamento do espetáculo, Repollo não entende a expressão "ante omnia", usada por Chirinos, confundindo-a com "Antona" e "Antoño", logo vem a incontida correção do culto Capacho. E esta provoca a alfinetada de Repollo: Capacho é "leído y escribido", locução familiar com que se zomba daquele que tem escassa cultura, mas que pretende passar por entendido; esta locução; porém, adquire aqui um matiz muito pitoresco, por partir justamente do analfabeto Repollo. Quanto ao nome de Capacho, se presta a curiosas interpretações: significa, entre outros, a "Zumaya", isto é, "ave de paso" (portanto, não presa a um lugar determinado) e que tem um "pico encorvado en la punta" Com um possível nariz curvo - donde seu nome - não seria Capacho o judeu ou cristão novo, muito mais culto que Repollo, o rústico cristão velho preso à terra? Estamos no terreno das conjeturas, apoiando-nos em parte na afirmação de Américo Castro, à qual nos referimos há pouco, e que diz respeito ao critério de escolha dos conselheiros de Carlos V

Os nomes do Regedor Juan Castrado e de sua filha - com a burlesca feminização - dão também margem a curiosas conotações, em perfeita sintonia com a outra condição exigida aos espectadores para que vejam o espetáculo: deverão ser filhos legítimos. Juan Castrado poderia ser pai de Juana? E poderia ser ele filho legítimo do casal Antonio Castrado e Juana Macha? O seu nome e o da filha levam, naturalmente, à conotação de ilegítimo ou adotivo, indicando, pois, sua impossibilidade de "ver" as maravilhas que os pícaros desenrolam diante de seus incrédulos olhos. mas crédulos por conveniência, seguindo o exemplo dado pelos Repollos, pai e filha, bem como pelo erudito Capacho.

Deixamos por último - mas nem por isso menos importante o nome carregado de saber humorístico: Tontonelo, o invisível criador do teatrinho mágico. O sábio Tontonelo - pois é ele assim chamado na peça - é originário da cidade de Tontonela, e só aparece através das referências dos pícaros manipuladores do espetáculo e dos enganados espectadores: "atontoneleada", "atontoneleados", são os neologismos empregados por Benito Repollo e por Juan Castrado, diante do prodigioso "Retablo", vazio, mas paradoxalmente repleto. Mas quem serão os tontos? Será Tontonelo? Ou serão os que caem no logro, acreditando ou fingindo acreditar que "vêem" as maravilhas apregoadas? E a ironia cervantina, a partir dos nomes das personagens, visando a ridicularizar as fraquezas humanas: Credulidade, o alto 
poder de sugestão? A auto-sugestão? Ou a imbecilidade de fingir crer no que não existe, por medo da opinião alheia?

Cervantes, o malicioso observador da condição humana e da natureza social, sabe lidar magicamente com os vocábulos, com os nomes, inoculando-lhes significados e fazendo que se tornem um recurso auxiliar, cômico, para a boa caracterização das personagens, dentro da estrutura simples e despretensiosa do entremez. 